\title{
DATACIÓNS ABSOLUTAS DE XACEMENTOS GALEGOS
}

\author{
SECCIÓN DE ARQUEOLOXÍA E PREHISTORIA*
}

O titular desta nota pode resultar enganoso pois se non trata de facer unha revisión completa ou valorativa das datacións absolutas de que se dispón até o momento para os xacementos arqueolóxicos de Galicia, o xeito daqueles publicados hai algúns anos paraEspaña ${ }^{1}$, senón de dar coñecemento público dunha serie de datas absolutas de xacementos que foron seleccionados hai máis de dez anos, dentro dun programa elaborado pola Sección de Prehistoria e Arqueoloxía do Instituto, e das que algunhas xa resultan coñecidas $^{2}$, ainda que non sempre coas precisións necesarias e que, por tanto, se usan dun xeito impreciso.

No ano 1979 as referencias cronolóxicas absolutas dos xacementos de

* Por encargo da Sección (F.F.B.) Francisco Fariña Busto.

${ }^{1}$ Cfr. a serie de traballos de M. ALMABRO GORBEA, Las fechas de C-14 para la prehistoria y la arqueología peninsular, Trabajos de Prehistoria, 27, 1970, 9 ss.; IDEM, C-14, 1971. Nuevas fechas para la prehistoria y la arqueología peninsular, TP. 28, 1971, 281 ss.; C-14. 1972. TP. 29, 1972, 228 ss.; IDEM, C-14. 1973. TP. 30, 311 ss.; IDEM, C-14. 1974. Cincuenta nuevas fechas para la prehistoria y la arqueología peninsular, TP. 31, 1974, 279 ss.; IDEM, C-14, 1975. Nuevas fechas. TP. 32, 1975. 167 ss.

${ }^{2}$ Véxase máis adiante as referencias á Chan de Coiro, castro Vixil e Castromao, e as respectivas notas.

"CUADERNOS DE ESTUDIOS GALLEGOS", Tomo XXXIX, Fascículo 104, Santiago 1991. 
Galicia eran $\operatorname{contadas}^{3}$ e, por ista razón, a Sección de Arqueoloxía e Prehistoria do Instituto promoveu a realización dunha campaña de toma de mostras -aproveitando traballos antigos dos que houbera mostras en cantidade e calidade suficiente, tomas de mostras das excavacións en curso, etc...- para a súa remisión ó Laboratorio de análise de C-14 do Instituto Rocasolano do Consello Superior de Investigacións Científicas (CSIC) despois dos contactos establecidos cos Dres. Fernán Alonso e Guillermo Del Río.

Os xacimentos seleccionados eran diversos tanto no que atinxe a tipoloxía das mostras como as etapas culturais que representaban, xa que no listado inicial se incluiron os seguintes: Buríz, Oirós, Argalo e A Parxubeira, dentro do megalítico; Regueiriño e Chan da Coiro, de Edade do Bronce; A Lanzada, Cameixa, Vixil e Castromao no castrexo. Ademáis prantexábase a conveñencia de aportar mostras distintas dentro dos mesmos xacimentos, como así ocurriu nos de Castromao, A Lanzada e Cameixa, dos que foi posible aportar mostras que permitían establecer correlación entre os diferentes niveis documentados nos propios xacimentos.

Diversas circunstancias, propias e alleas, incluídas algunhas derivadas da imposibilidade de conseguir volumen suficiente dalgunhas mostras para verificar o análise como ocurriu con algúns dos niveis de $\mathrm{A}$ Lanzada, foron demorando a obtención das datas, que nós foron remitidas en diversas partidas e das que, agardando o momento de dalas a coñecerconxuntamente, algunhas foron saindo como referencias imprecisas e outras de xeito completo. Parece oportuno dalas a coñecer todas con algunhas indicacións complementarias que permitan unha valoración inicial delas, endeben podan e deban ser obxecto de estudo e valoración máis polo miudo e mesmo contraste coas outras datas que en número crecente se van coñecendo en Galicia ${ }^{4}$.

\footnotetext{
${ }^{3}$ Prácticamente cinguianse a data primeira de Borneiro (J.J. EIROA, Una fecha radiocarbónica para el NW. Peninsular, Estudios, Zaragoza, 1973, 48 ss.) e a de Penarrubia CF. ARIAS VILAS, El castro de Penarrubia (Lugo) y la novedad de su datación por C-14, Actas del XV C.A.N. Lugo, 1977 (Zaragoza, 1979) 613-622.

${ }^{4}$ As datas $\mathrm{C}-14$ que existen hoxendía en Galicia son relativamente abundantes, ainda que estemos moi lonxe de dispoñer de secuencias completas, con coherencia interna dentro dun mesmo xacemento e con valoración das correlacións que poden existir entre todas elas. A bibliografía de detalle e amplia e en constante aumento, polo que duas referencias xerais poden permitir o acceso a información puntual e concreta. Para o mundo megalítico pódese consultar R. FABREGAS VALCARCE, Megalitismo en Galicia, TAE. Coloquio de Arqueoloxía do Noroeste Peninsular. XXVIII, 1988, 57-78.
}

"CUADERNOS DE ESTUDIOS GALLEGOS", Tomo XXXIX, Fascículo 104, Santiago 1991. 
As datas que temos recibido oficialmente na Sección corresponden os xacementos da Chan de Coiro, Castro de Vixil, Castro de Cameixa e Castromao, e agardamos coñecer os resultados de Lanzada e dalgún outro conxunto megalítico.

\section{A Chan de Coiro.}

O xacemento corresponde a unha descoberta casual na que se atoparon restos de uteis diversos, interpretados inicialmente como campaniformes, asociados a unha estructura constructiva entendida como fondo de cabana. $\mathrm{O}$ achado casual ó abrir unha pista forestal permitir realizar unha toma de mostras de carbón das que se remitiu unha para a súa análise que ofrece os resultados seguintes:

A Chan, Coiro, Cangas de Morrazo, Pontevedra.

Mostra O-CH, 057.

Material: carbón vexetal.

Edade C-14. $3830 \pm 80$ anos.

Edade equivalente: 1880 anos a.C.

Referencia laboratorio: CSIC-770.

A data facilitouna de xeito público no Coloquio de Arqueoloxía do Noroeste Peninsular. Porto-Baiao, 22-24 setembro 1990, o Dr. Fernán Alonso, tal e como se recolle no volumen das Actas 5 . O conxunto arqueolóxico é obxecto de estudo e próxima publicación ${ }^{6}$.

\section{Castro de Vixil.}

Neste xacimento da Terra Chá lucense téñense efectuado algunhas catas e labores de prospección superficial con abundante colleita de material aproveitando labores ocasionais e os traballos dunha canteira, que permitiron apreciar a estratigrafía ocupacional, tipificando un nivel de ocupación pechado por unha capa continua de incendio, nivel do que procede a mostra. A análise polínica realizada no propio xacemento permitíu establecer unha

Para a cultura castrexa ainda debemos agardar o estudo que X. CARBALLO ARCEO ten no prelo, pero no entanto pode ser útil J.J. EIROA, La cultura castreña del noroeste de la Península Ibérica 15 años después. Anales de Prehistoria y Arqueología. Murcia. 4, 1988, 111-123, que recolle moitas das datacións existentes.

${ }^{5}$ Coloquio de Arqueoloxía do Noroeste. Porto-Baiao, 22-24 setembro 1988. TAE. XXVIII, 1988, esp. 190-191 e 82. Asemade, no mesmo volumen Monserrat García-Lastra Merino, Aportación a la cronología campoaniforme del Noroeste. ibidem, 175-179.

${ }^{6} \mathrm{O}$ membro colaborador da Sección, don Xosé Suárez Otero, ten preparado un estudo sobre o conxunto no marco da súa tese doctoral. 
secuencia concordante coa apreciada no castro de Penarrubia, para o que tamén se conta cunha datación absoluta ${ }^{7}$.

Castro de Vixil, Boizán, Villalba, Lugo.

Carbón vexetal

Edade C-14: $2070 \pm 50$ años.

Edade equivalente: 120 a.C.

Referencia laboratorio: CSIC-610.

No curso dos traballos de muestreo para a análise polínica recolléronse outras mostras, que permitiron establecer unha data moi semellante: 2060 B.P. (CSIC-633), o que parece refrendar a homoxeneidade do nivel de destrucción ${ }^{8}$.

\section{Castro de Cameixa.}

As excavacións do castro de Cameixa, realizadas en dúas campañas, 1944 e 1945, por Xaquín Lorenzo e Florentino López Cuevillas aportaron a novidade de documentar a existencia dunha serie de niveis de ocupación superpostos, circunstancia que durante moitos anos se considerou excepcional e lle confería unha indudable novidade e interese, convirtindo ó xacemento en punto de referencia bibliográfica continua9. A colleita de materiais orgánicos carbonizados durante os traballos e a súa conservación no Museo Arqueolóxico Provincial de Ourense propiciaron a posibilidade de analizar e, consecuentemente datar de xeito absoluto e referenciados

${ }^{7}$ Cfr. a nota 3.

${ }^{8}$ M.J. AIRA RODRIGUEZ e F. GUITIAN OJEA, Contribución al estudio de la cultura castreña gallega: análisis palinológico de los castros de Vixil y Penarrubia (Lugo), Pontevedra Arqueológica, II, 1985-86, 191-200, esp. 193.

${ }^{9}$ A bibliografía sobre Cameixa escomenza coas referencias á estación nun artigo xeral de Cuevillas e Lorenzo, pero a máis detallada é: Notas arqueolóxicas sobre o castro de Cameixa, RG. LVIII, 1948. Con posterioridade publicáronse varios aspectos de detalle sobre o xacemento, até que en 1986, na ocasión do Centenario de nacemento de Cuevillas deuse a coñecer a memoria dos traballos realizados. F. LOPEZ CUEVILLAS e X. LORENZO FERNANDEZ, Castro de Cameixa. Xunta de Galicia. Informes. Santiago, 1986.

Cameixa é obxecto de referencias concretas e específicas nos traballos de síntesis de J. MALUQUER, en el vol. III de la Historia de España de Ramón Menéndez Pidal, e noutros traballos xerais como o publicado nas Actas das xornadas de metodoloxía histórica de Santiago de Compostela, 1973. Tamén A. Blanco Freijeiro, La cultura castrexa, Simposium de Prehistoria Peninsular. Pamplona, 1960. E outros con posterioridade como F. ACUÑA, Panorámica da cultura castrexa, Bracara Augusta, 1973, e F. Fariña Busto e alii. Panorama xeral da cultura castrexa, en Estudos de cultura castrexa e historia antiga de Galicia (X. Pereira, ed.) Santiago, 1983.

"CUADERNOS DE ESTUDIOS GALLEGOS", Tomo XXXIX, Fascículo 104, Santiago 1991. 
entre iles os diferentes niveis, ainda que o material dispoñible somentes permitíu a datación efectiva de dous dos niveis dos catro potenciais. A publicación posterior do relatorio de excavación permitirá, sen dúbida, unha meirante contribución o coñecemento e valoración dos materiais deste xacemento no que se abren interesantes perspectivas namentras que outras poden ser pechadas.

Castro de Cameixa. Cameixa, Boborás, Ourense.

Mostra CA-4, nivel IV.

Material: Belotas carbonizadas.

Edade C-14: $1970 \pm 50$ anos.

Edade equivalente: 20 anos a.C.

Referencia laboratorio: CSIC-742.

Castro de Cameixa. Cameixa, Boborás, Ourense.

Mostra CA.3, nivel III.

Carbón vexetal.

Edade C-14: $2030 \pm 40$ anos.

Edade equivalente: 80 anos a.C.

Referencia laboratorio: CSIC-743.

Ainda a reserva dunha máis detallada análise debemos chamar a atención verbo da corrección cronolóxica que ofrecen internamente as datas absolutas, xa que responden a momentos sucesivos da ocupación, sen marcadas discontinuidades entre os materiais. Magoaé que se non poidesen completar as análises dos niveis inferiores, tanto por ver se se mantiña a coherencia interna como pola datación absoluta propiamente dita.

\section{Castromao.}

O conxunto arqueolóxico de Castromao engloba unha dualidade evidente xa que a continua observación desta estación e as sucesivas etapas da súa excavación períitennos apreciar hoxendía as diferencias entre o castro e os seus niveis de ocupación e o asentamento da cidade romana, ainda por excavar. As mostras ás que se refiren as análises corresponden todas a etapa cultural castrexa (cando menos así as temos considerado sempre e as datacións confirman a nosa sospeita, dito sexa coas reservas coas que sempre compre valorar o feito), e tomáronse no curso dos traballos de campaña de 1981 en diversos puntos do xacimento que mantiñan relación entre eles ${ }^{10}$.

\footnotetext{
${ }^{10}$ Unha revisión da problemática xeral do xacimento coas referencias da bibliografía anterior en F. FARIÑA BUSTO, Dos notas a propósito de Castromao. CEGal, no prelo.
}

"CUADERNOS DE ESTUDIOS GALLEGOS", Tomo XXXIX, Fascículo 104, Santiago 1991. 
Castromao. Castromao, Celanova, Ourense.

Mostra OR-01. C-81, cadro A-2, nivel 5.

Carbón vexetal.

Edade C-14. $7180 \pm 60$ anos.

Edade equivalente: 5230 anos.

Referencia laboratorio: CSIC-637.

Castromao. Castromao, Celanova, Ourense.

Mostra OR-01, rep.

Carbón vexetal.

Edade C-14. $7200 \pm 60$ anos.

Edade equivalente: 5250 anos.

Referencia laboratorio: CSIC-637-R.

Esta mostra foi contraste da anterior, por mor da disparidade que presentaba coa data que se supón arqueolóxicamente para o nivel correspondente. Agora ben, como noutros casos estas distorsiones non deben ser obxecto de xuicio crítico indiscriminado, senón de reflexión sobre o método e mesmo sobre as posibles causas da distorsión ${ }^{11}$.

Castromao. Castromao, Celanova, Ourense.

Mostra OR-02. C-81. Corte A, nivel 8.

Carbón vexetal.

Edade C-14. $2370 \pm 50$ anos.

Edade equivalente: 420 anos.

Referencia laboratorio: CSIC-638.

Castromao. Castromao, Celanova, Ourense.

Mostra OR-03. C-81. Sector B, nivel 10.

Carbón vexetal.

Edade C-14. $2330 \pm 50$ anos.

Edade equivalente: 380 anos.

Referencia laboratorio: CSIC-639

Castromao. Castromao, Celanova, Ourense.

Mostra OR-04. C-81. Corte E, nivel 7.

Carbón vexetal.

Edade C-14. $2250 \pm 50$ anos.

\footnotetext{
${ }^{11}$ Vide a este propósito as reflexións de Fernán Alonso cit. na nota 5. A propósito de datas con problemas semellantes A. ESPARZA ARROYO, Los castros de la Edad del hierro del Noroeste de Zamora. Zamora, 1986, esp. 400 ss.
}

"CUADERNOS DE ESTUDIOS GALLEGOS", Tomo XXXIX, Fascículo 104, Santiago 1991. 
Edade Equivalente: 300 anos.

Referencia laboratorio: CSIC-640.

Unha valoración máis polo miudo destas datas, a que se poidera deducir delas en comparanza con outras e mesmo as reflexións que se poderían derivar da súa presentación calibrada, require outros prantexamentos que non caben agora eiquí, polo que comprirá, como nos restantes casos, agardar a novas contribucións que permitan integrar istes datos no contexto xeral das datacións carbono 14 de Galicia.

Finalmente, como colofón a esta breve nota, desexar a utilidade dos datos que se aportan e lamentar que non todas as datacións daquela propostas chegaran a concretarse, endeben estamos seguros que moitas das que son hoxe coñecidas tiveron algo en común cos prantexamentos que hai unha ducia de anos motivaron a colleita destas que agora ofrecemos.

"CUADERNOS DE ESTUDIOS GALLEGOS", Tomo XXXIX, Fascículo 104, Santiago 1991. 